\title{
Research and Analysis on the Mutual Restriction Factors Between Green Finance and New Energy Power Industry
}

\author{
Keyuan Jin, Zefeng Ruan \\ School of Economics and Management, North China Electric Power University, Beijing, China \\ Email address: \\ jinkeyuan123456@163.com (Keyuan Jin),536716@2077.hk (Zefeng Ruan)
}

\section{To cite this article:}

Keyuan Jin, Zefeng Ruan. Research and Analysis on the Mutual Restriction Factors Between Green Finance and New Energy Power Industry. International Journal of Economics, Finance and Management Sciences. Vol. 8, No. 6, 2020, pp. 224-230. doi: 10.11648/j.ijefm.20200806.13

Received: November 3, 2020; Accepted: November 26, 2020; Published: November 27, 2020

\begin{abstract}
For the past few years, green finance, as one of the most important means of sustainable development, has been widely concerned by scholars at home and abroad. The development of new energy power industry is rapid, and the application of green finance is more and more extensive. The integration of the green finance and new energy power industry is conducive to promoting the construction of ecological civilization in China. However, due to the relatively backward development of green finance, the new energy power industry also has some limitations, resulting in defects in the integration of the two. This paper first describes the current situation of the support of green finance to the development of China's new energy power industry, and the mechanism of green finance supporting the new energy power industry, that is, the effect of capital aggregation and the effect of scientific and technological innovation. On this basis, it further analyzes the bottleneck constraints in the process of the two docking, such as insufficient supply of green financial products, low level of innovation, imperfect laws and regulations, etc. Finally, the paper puts forward some suggestions on how to realize the connection between new energy industry and power industry. The content is novel and frontier.
\end{abstract}

Keywords: Green Finance, New Energy Power Industry, Support Status, Bottleneck Constraints

\section{Introduction}

\subsection{Background Analysis}

\subsubsection{The New Energy Power Industry Is Developing Rapidly and Has a Good Development Prospect}

China has grown into the largest and fastest growing new energy grid in the world. Since 2010, China has collected more than 400 billion yuan funds through renewable energy surcharge, all of which are used to support the development of new energy industry. By 2018, the cumulative installed capacity of wind power and photoelectricity in China has reached 185 million kilowatts and 176 million kilowatts, respectively, which is 4 times and 200 times larger than that in 2010. Wind power and photoelectricity power generation also achieved rapid growth, with a total of 420 billion Kilowatt-hour in 2017.

During the Period of The Fourteenth Five-Year Plan, China's new energy installed capacity will exceed 800 million kilowatts, accounting for $29 \%$ of the installed capacity, and annual power generation will reach 1.5 trillion Kilowatt-hour. According to the data previously released by State Grid Energy
Research Institute Co., Ltd., by the end of 2019, the installed capacity of new energy power generation in China was 410 million kilowatts, accounting for $20.6 \%$ of the total installed capacity in China; the national new energy power generation capacity was 630.2 billion Kilowatt-hour, up 16\% year-on-year, accounting for $8.6 \%$ of the total national power generation.

\subsubsection{The Application of Green Finance in New Energy Power Industry Is More and More Extensive}

"2018 China new energy power investment and Financing Conference" was held in Guangzhou green finance reform and innovation pilot zone. The conference focused on green finance and sought ways to broaden the development of new energy power industry.

On October 19 of the same year, at the "sub forum of green finance promoting energy transformation" of "2018 international energy change forum", Zhou Haibing, vice president of GCL new energy, said that capital is the booster of energy industry development, and capital oriented effect can effectively promote the structural optimization of energy industry. To promote the energy reform, especially in the context of the sharp decline in 
the cost of photoelectricity products, green finance has become one of the core elements for solar power generation to achieve affordable access to the Internet in a wider range of the world, and to promote energy reform.

\subsection{Value Analysis}

At present, there are few researches on the application of green finance in the field of new energy and electric power in China, and the application of green finance in the field of new energy and power is still in the initial stage of development. The purpose of this paper is to deeply analyze the current situation of green finance supporting the development of China's new energy power industry and the bottleneck constraints existing in the connection between the two, and put forward feasible and constructive countermeasures and suggestions on how to better realize the accurate docking of green finance and new energy power industry, which is novel and cutting-edge.

\subsection{Literature Review}

\subsubsection{Research on Green Finance and Its Development}

Xu Feng (2018) first analyzed the current situation of green finance development in Beijing after the promulgation of the measures, and extracted the problems to be faced in the current development of Green Finance: difficult operation of green finance, immature green financial mechanism, imperfect green financial laws and regulations [1]. Zhao Liang (2018) sorted out the relevant research on green finance at home and abroad from three aspects of green products, economic benefits and social responsibility, and provided suggestions for the development of green finance in China from three aspects: market operation, tax policy and legal system [2]. Liu Xia (2019) selected the green credit ratio, per capita GDP and other relevant data of six provinces in Central China (Henan, Jiangxi, Anhui, Shanxi, Hubei and Hunan) from 2004 to 2017, and analyzed them by using the fixed effect model. It shows that green finance can promote the growth of regional economy, so it is necessary to develop green finance [3]. Du Li (2019) pointed out that at present, China's research on green financial policy and green financial policy system is still in its infancy. Therefore, we should strengthen the reform of fiscal policy, environmental protection tax, pollutant emission, performance assessment, financial market infrastructure construction and green insurance [4]. Xia Wenbin (2020) understood the current situation of green finance development in China by combing the characteristics of green finance in representative provinces (regions), and concluded that although China's green finance is still in the primary stage of development, in recent years, the state has paid more attention to green finance, and China's green financial system is gradually improving [5]. Pei Yingzhu (2020) analyzed and demonstrated the concept, development status, necessity, conditions and practical dilemma of basic development of green finance, and concluded the current practical difficulties of green finance development in the Pearl River Xijiang economic belt: the participation and effectiveness of the main body in the green financial market is not high, the green financial products and services are insufficient, and the green financial information data is flat Taiwan construction lags behind, and puts forward the corresponding countermeasures [6].

\subsubsection{Research on Green Finance Supporting the Development of New Energy Industry}

Focusing on the background of supply side reform, Li Wenda (2017) proposed that the problems in the process of green financial policy supporting the optimization and transformation of energy industrial structure are still very serious, and the government, financial system, enterprises and the third party should play a joint role in promoting the implementation of energy green financial policy [7]. $\mathrm{Xu}$ Sheng (2018) pointed out that green credit mainly affects the industrial structure through the capital and capital channels of enterprises. In the process of promoting the green transformation of industrial development, it is necessary to adjust the credit structure based on the market, reasonably allocate the green credit funds, and promote the optimization and upgrading of the industrial structure [8]. Zhang Fangjing (2018) analyzed the development path of green finance in China's energy industry since the new normal, and proposed that the development of green finance in China under the new normal has the characteristics of fast speed, low quality and strong policy dependence. It is necessary to improve the green financial service system and actively guide commercial banks and social third-party institutions to participate in the development [9]. Shi Xinyi (2019) pointed out that the bank credit business has a single financing form for clean energy enterprises. Therefore, it is necessary to improve the guiding role of the government, actively build a green information platform and strengthen the third-party supervision [10]. Ji Qinwen (2020) pointed out that green finance has the functions of resource allocation, information disclosure and risk control, which can promote industrial integration, promote industrial green upgrading and support the development of new energy industry [11].

\section{The Support Status of Green Finance to New Energy Power Industry}

\subsection{Main Types of New Energy Power Industry in China}

The main energy sources of China's new energy power industry are solar energy, wind energy, hydro energy, biomass energy, nuclear energy and geothermal energy. The support of green finance to the new energy power industry is mainly reflected in the following aspects.

\subsubsection{Photoelectricity}

As an important tool of green development, photovoltaic has attracted the attention of most financial institutions. In the next development, more and more financial institutions will cooperate with photovoltaic enterprises to increase support for the photovoltaic industry chain through project loans, working capital loans, photovoltaic poverty alleviation loans, and photovoltaic consumption loans, so as to jointly promote the 
development of the photovoltaic industry. But at present, there are still some problems in the development of Optoelectronics in China, such as cash flow, asset evaluation and so on.

\subsubsection{Wind Power}

Wind power is a capital intensive and technology intensive industry. Green bonds require closed management of raised funds to invest in green industries, enhance environmental information disclosure and green certification of third-party assessment institutions, and provide new financial support for wind power industry. In practice, green financial products are still faced with high business risks and low returns, imperfect information communication mechanism, and imperfect relevant policies.

\subsubsection{Hydropower}

Hydropower generation is to convert the potential energy contained in rivers and lakes into kinetic energy of water turbine, and then the turbine is used as the driving force to drive the generator to generate electricity. If another kind of mechanical generator is connected to the turbine, electricity can be generated with the rotation of the turbine, and then the mechanical energy will be converted into electrical energy. Hydropower is the most advantageous new energy power industry, but it is not good for river ecosystem. Compared with thermal power generation, hydropower generation is also of great significance.

\subsection{Application Status of Green Financial Products in New Energy Power Industry}

\subsubsection{Application Status of Green Credit in New Energy Power Industry}

In terms of green credit, the balance of green credit loans has continued to increase since 2013, mainly in hydropower, wind power and solar energy. From the green credit balance of different projects, from the end of June 2013 to the end of June 2017, the green credit balance of solar energy projects increased by $307.34 \%$, wind power projects increased by $114.38 \%$, and hydropower projects increased by $21.52 \%$. The loan balance of renewable energy and clean energy projects in the green credit is 1610.32 billion yuan, of which the largest is hydropower project with the amount of 753.58 billion yuan; the second largest is wind power project with the amount of 473.15 billion yuan; the third largest is solar energy project, with the amount of 201.86 billion yuan; the fourth largest is other projects, with the amount of 127.97 billion yuan [12].

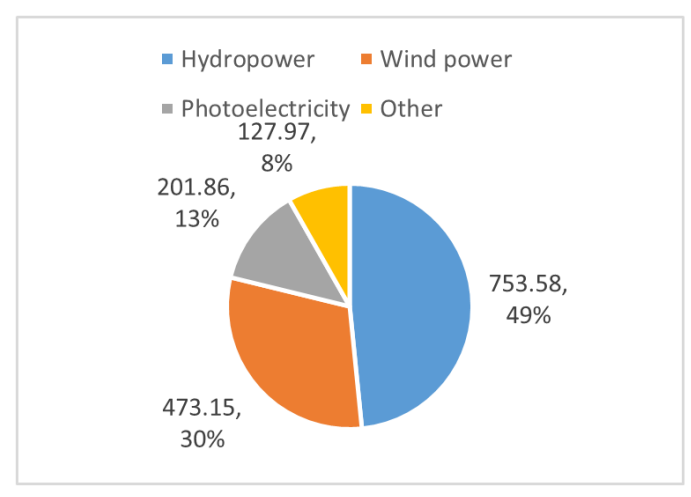

Figure 1. Green credit balance (Unit: billion yuan).

\subsubsection{Application Status of Green Bonds in New Energy Power Industry}

In recent years, the state has gradually increased its investment in the field of new energy. In 2018, the funds raised by green bonds of non-financial enterprises were mainly used in the fields of clean energy and clean transportation, accounting for $47 \%$ of the total investment. In 2019, China's green bonds raised 3.479 billion yuan in the field of new energy and power, mainly focusing on hydropower, wind power and wind power. In the next 20 years, hydropower, wind power and Optoelectronics will become the main force in the development of power industry. In the future, investment in clean energy will continue to increase.

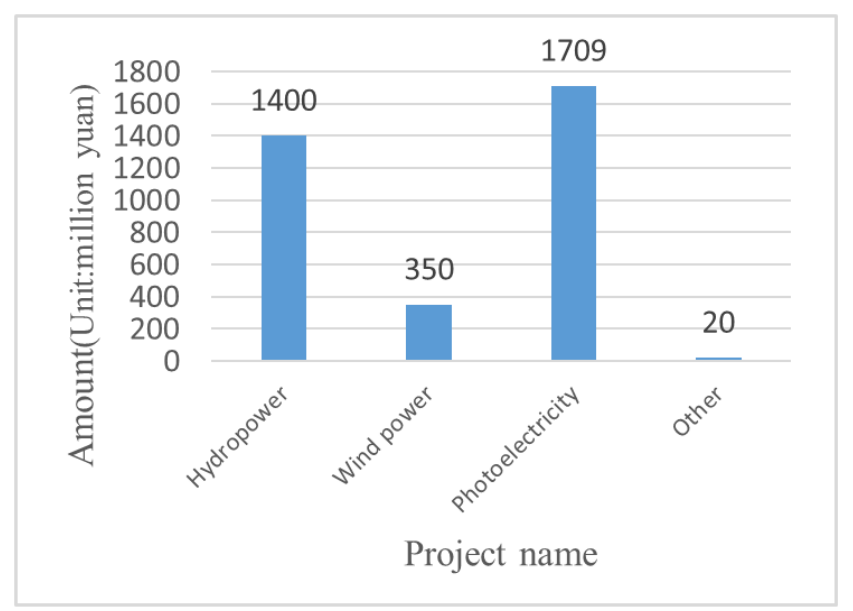

Figure 2. Utilization of funds raised by green bonds in 2019.

\subsection{Effect Mechanism of Green Finance Supporting New Energy Power Industry}

\subsubsection{Capital Aggregation Effect}

The capital accumulation effect of Green Finance on the development of new energy power industry is mainly realized through two channels: capitalization process and cross regional resource allocation process [13].

The process of capitalization is the process of transforming available resources into profitable and commercial capital on the basis of the existing market and institutional system, and realizing the optimal allocation of new energy power industry through the operation of capital market. First of all, the capitalization process provides financial support for enterprises and improves the financing efficiency of enterprises. At present, most of the small and medium-sized new energy power enterprises have limited financial resources, and most of them have financing difficulties. Therefore, the full use of green credit, green bonds and other green financial instruments for financing, can effectively reduce the cost of enterprise financing, improve the efficiency of enterprise financing. Secondly, the process of capitalization changes the traditional single financing mode and provides more financing channels for enterprises. Finally, capitalization can strengthen corporate governance by improving the existing corporate governance structure and improving the enterprise management mechanism. At the same time, the market competition factors are introduced 
into the enterprise governance system to promote the new energy power enterprises to continuously carry out technological innovation and product research and development under the pressure of external competition, so as to improve the core competitiveness.

Cross regional resource allocation is to realize the optimal allocation of resources through the high integration of resources and capital. China has a vast territory and rich resources, but the distribution is very uneven. For example, wind energy, water energy, solar energy and other resources are mainly concentrated in the western region, but the capital distribution in this region is insufficient. Therefore, through the high integration of resources and capital between different regions, the capital needs of the development of new energy power industry can be met, the optimal allocation of resources in the whole industrial system can be realized, and the whole industry can be developed rapidly.

\subsubsection{Effect of Science and Technology Innovation}

The scientific and technological innovation effect of Green Finance on the development of new energy power industry is mainly realized through the information processing function of financial system, so as to reduce the information cost and control the risk [14]. First of all, when the new energy and power technology innovation project is launched, the relevant information will be disclosed in the relevant financial system, through which investors can obtain relevant information quickly and cheaply. Then, the information processing function of the financial system can audit the relevant information of enterprises and investors, and publish it on the website, which helps to effectively play the role of market supervision; at the same time, financial institutions can serve as a hub for the connection between the two, providing investors with a risk isolation zone and effectively controlling market risks.

\section{Bottleneck Constraints of Precise Docking Between Green Finance and New Energy Power Industry}

\subsection{The Overall Supply of Green Financial Products to the New Energy Power Industry Is Insufficient, Which Hinders the Financing of Enterprises}

In 2018, China's total demand for green finance funds was 2.1 trillion yuan, but the total supply was only 1.3 trillion yuan, and the gap between supply and demand was 800 billion yuan. Among them, the sustainable energy sector was the sector with the largest capital demand, the total capital demand was 697.6 billion yuan, the total capital supply was 258.6 billion yuan, and the supply and demand fund gap was 438 billion yuan. Although China's green finance has achieved rapid development under the joint efforts of supply and demand in 2018 , the total supply of green financial funds is still seriously insufficient. In 2019, the new demand for green finance is 2.048 trillion yuan, but the supply of new green capital in 2019 is only 1.43 trillion yuan, and the gap of new supply and demand funds in 2019 is 618 billion yuan, and the gap of green financial funds is still increasing.

The development of China's green financial market is not mature, which hinders the supply of green financial products. The research on green finance in China started late. In 2016, the guiding opinions on the construction of green financial system defined green finance and green financial system for the first time, and put forward the significance of building green financial system. Since then, China's green financial market began to develop. At present, China's green finance is still in the early stage of development, and the green financial system in China has not yet been completed, which hinders the development of green finance in China to a certain extent.

Due to the information asymmetry between financial institutions and new energy power industry, the contradiction between supply and demand of green finance is further aggravated [15]. For financial institutions, the investment risk of energy industry is high and the return period is long. Before providing green financial products for enterprises, it is necessary to conduct a comprehensive evaluation on the business status, property status and the use of green financial products. However, due to the information asymmetry, financial institutions can not judge whether the data and materials provided by enterprises are true and effective, and it is difficult to evaluate the enterprises objectively. As a result, the risk of financial institutions providing green financial products is greatly increased and the supply of green financial products is reduced.

At present, the supply and demand of green financial products in China is extremely unbalanced. The supply of green financial products is far less than the demand. The immature development of green financial market and information asymmetry between financial institutions and new energy power industry will hinder the supply of green financial products, which will lead to the financing obstacles of new energy power enterprises.

\subsection{The Low Level of Green Financial Innovation Hinders the Effect of Scientific and Technological Innovation}

At present, the products and services provided by China's green financial institutions are single, and the green financial products in the market are mainly based on the traditional green credit and green bonds, and lack of innovative services, products and financing mechanisms, which can not meet the diversified financing needs of the new energy power industry and hinder enterprises from developing new energy projects [16]. There is a large demand for funds for new energy industry projects, such as wind power generation projects. More than $80 \%$ of the funds are from debt financing, which leads to a very fragile capital chain, high asset liability ratio, great financial risk and slow development of enterprises. The single variety of financial products and the lag of supporting services directly affect the progress of project construction and the production and operation of enterprises, especially the development of small and medium-sized enterprises with weak capital.

The low innovation level of green finance hinders the financing of new energy projects, and the information processing function of the financial system can not fully play a 
role, resulting in the failure of green finance to provide financial support and risk transfer mechanism for the technology research and development of new energy projects, and can not achieve the purpose of reducing information costs and controlling risks.

\subsection{The Development of New Energy Power Is Hindered by Internal and External Factors}

First of all, the cost of developing new energy power projects is high. At present, the average generation cost (average, yuan / $\mathrm{kWh}$ ) of various forms of power generation in China is as follows: thermal power is 0.3 yuan / $\mathrm{kWh}$ (with desulfurization device), hydropower is 0.4 yuan / $\mathrm{kWh}$, nuclear power is 0.9 yuan / $\mathrm{kWh}$, wind power is 0.5 yuan / $\mathrm{kWh}$, and solar photovoltaic power generation is 3.3 yuan / $\mathrm{kWh}$. The advantage of wind power lies in that the cost of wind power has been basically determined after the completion of the project, it will not fluctuate with the energy price during the operation of the project, and it shows a downward trend from the historical trend. Although China has abundant offshore wind power reserves, it is still in the initial stage, so the cost of wind power generation is still not advantageous. In general, the cost of new energy power projects is higher than that of traditional thermal power generation. In terms of power generation cost, new energy power industry has no advantage.

Secondly, new energy power projects are greatly affected by environment and time, and power generation is cyclical. Wind power needs to consider human factors. Photovoltaic power generation project covers a large area and has special construction site requirements. If some of them are built in desert areas, it is difficult to construct and maintain the project. Wind power project equipment must be built in areas rich in wind resources, most of which are located in densely populated areas, so the construction is quite affected by human factors. At the same time, hydropower, wind power and photovoltaic projects all have the periodicity of power generation, and the efficiency varies greatly in different seasons. Hydropower and photovoltaic projects generate more electricity in summer, while wind power projects generate more power in spring, which leads to unstable power supply.

Finally, China's new energy power industry development innovation is low. One is the lack of innovative construction enterprise management mechanism, enterprise management lack of innovative spirit and innovation ability, can not play a good guiding role, leading to poor economic benefits of enterprises, seriously affecting the construction of power engineering. Second, the lack of core technology. The development of China's new energy power industry relies heavily on foreign advanced technology and equipment, and domestic independent design, manufacturing and independent innovation are not enough. Taking the photovoltaic industry as an example, China has formed a complete solar photovoltaic industry chain, but China's photovoltaic industry still has the disadvantage of high dependence on key equipment in the manufacturing industry. Most of the key equipment for solar cell production comes from foreign suppliers, and the cost of imported equipment accounts for about $80 \%$ of the equipment cost of enterprises. The basic research of the enterprise itself is weak, the innovative and basic research work is carried out less, and the independent core technology is lack [17].

\subsection{Green Finance Related Laws and Regulations Are Still Lacking}

Green finance law is a financial law that runs through the concept of environmental protection, but at present, China has not formulated a special green financial law, only issued some relevant laws and regulations. Therefore, China's green financial law is still deficient, which is far from enough for the healthy development of green finance. It can be shown in the following two aspects: first, the level of legislation is low. The main body of formulating the existing legal documents on green finance in China is the State Council and relevant ministries and commissions, and there is no special green financial law formulated by the supreme state authority. The legal documents with lower rank have insufficient authority, systematicness, pertinence and compulsion, and have low legal effect, which can not restrain and deter the violators. Second, the content is not comprehensive, the development of green finance in China started late, leading to the lack of content of green finance law. At present, most of the relevant laws and regulations that have been issued tend to pollution control, and there are few laws and regulations for new energy and environmental protection enterprises.

When new energy power enterprises invest and finance green financial products, they should first evaluate the products. However, due to the imperfection of the legal system, it is difficult to unify the evaluation standards, which hinders the investment and financing activities of enterprises.

\section{Policy Suggestion}

\subsection{Increase in Supply of Green Financial Products}

Green financial products need to increase their supply and alleviate the contradiction between supply and demand of green financial products in order to effectively serve the investment and financing activities of new energy power enterprises.

First of all, it is necessary to build a bridge of information exchange between financial institutions and new energy power industry, such as setting up special information management institutions. Financial institutions and enterprises need to submit the relevant materials for investment and financing activities to special information management institutions, which will review the materials of both parties to ensure the authenticity and effectiveness of the information, and then send the materials to the other party of the transaction, so as to ensure that the two parties can obtain the true and comprehensive relevant information of the other party. This can reduce the risk of financial institutions to provide green financial products and promote the supply of green financial products.

Secondly, enterprises should reasonably introduce foreign 
capital and make use of foreign capital through multiple channels, including listing abroad and introducing foreign venture capital to promote the development of new energy power projects.

\subsection{Promote the Innovation of Green Finance and New Energy Power Industry}

First of all, we need to promote green financial technology innovation and product innovation. Green finance should reasonably use big data, cloud computing and other scientific and technological means [18], collect and sort out green financial business data, customer demand information, etc., establish a green finance database through big data and cloud computing, predict the demand of green financial products according to the historical data in the database, and make innovation and improvement according to the customer demand information, so as to meet customers' demand for green finance Product requirements. At the same time, we also need to cultivate a large number of green financial innovative talents to carry out the R \& D and innovation of new green financial products, and strive to expand the coverage of green financial products to meet the needs of green financing of various enterprises.

Secondly, it is necessary to promote technological innovation, equipment innovation and management mechanism innovation of new energy power industry. China should vigorously cultivate and introduce high-end talents related to the new energy and electric power industry, develop new technologies and equipment and formulate new management mechanism on the basis of learning foreign advanced knowledge. We should strengthen independent innovation, strengthen the dominant position of enterprises in scientific and technological innovation, and promote power enterprises to achieve breakthroughs in core technology, high-end equipment, and scientific and technological innovation.

\subsection{Improve Green Finance Related Laws and Regulations}

The healthy development of green finance needs to establish and improve the legal system of green finance. First of all, it is necessary for the state authority to formulate the green financial law. The formulation of green finance law can standardize the definition and scope of green finance, eliminate the obstacles to the development of green finance due to different local policies, and provide guarantee for the development and innovation of green finance. Secondly, it is necessary to clarify the green financial regulatory institutions and implement the legal supervision of green finance. In the supervision and legislation of green finance, detailed and operational business rules should be formulated to effectively prevent and control environmental risks.

\section{Conclusion}

This paper aims to analyze the current situation of green finance's support for the development of China's new energy power industry and the bottleneck constraints existing in their docking, and put forward targeted suggestions on how to accurately connect the two. According to this study, there are still many deficiencies in the development of China's new energy power industry and green finance. In the process of integration development, they are restricted by four factors: insufficient supply of green finance, low level of innovation, imperfect laws and regulations, and lack of self-development of new energy power industry. Through the observation of industry phenomenon, the understanding of theoretical knowledge and data analysis, the author puts forward some suggestions for the above problems, namely, increasing the supply of green financial products, promoting the innovation of green finance and new energy power industry, and improving the relevant laws and regulations of green finance. To promote the integration and development of green finance and new energy power industry.

\section{References}

[1] Xu Feng, Wang Weihua, Ma Xintong, Xiao Feng. Analysis on the current situation and problems of green finance development in Beijing [J]. North economic and trade, 2018 (11): 110-111

[2] Zhao Liang. Review of green finance theory research [J]. Modern business industry, 2018, 39 (19): 106-108.

[3] Liu Xia, he Peng. Impact of Green Finance on economic development in Central China [J]. Industrial technology economy, 2019, 38 (03): 76-84.

[4] Du Li, Zheng Lichun. Effect evaluation of China's green financial policy system: an analysis based on pilot operation data [J]. Journal of Tsinghua University (PHILOSOPHY AND SOCIAL SCIENCES), 2019, 34 (01): 173-182 + 199.

[5] Xia Wenbin, Guo Xianjun. Development status and practical innovation of regional green finance in China [J]. Modern enterprise, 2020 (05): 57-58.

[6] Pei Yingzhu. Dilemma and outlet of green finance development -- Taking Pearl River Xijiang economic belt as an example [J]. Coastal enterprises and science and technology, 2020 (01): 48-53.

[7] Li wenda. Research on green financial policy support for China's energy transformation under the background of supply side Reform [D]. Xi'an University of science and technology, 2017.

[8] Xu Sheng, Zhao Xinxin, Yao Shuang. The impact of green credit on industrial structure upgrading [J]. Journal of Shanghai University of Finance and economics, 2018, 20 (02): 59-72.

[9] Zhang Fangjing. Analysis on the development path of green finance in energy industry under the new normal [J]. Times finance, 2018 (32): 68.

[10] Shi Xinyi. Research on the development of green financial business in Hebei Province [D]. Hebei Normal University, 2019.

[11] Ji Qinwen, Zhao Jiahui. Research on the coupling mechanism of green finance and new energy industry in Jiangsu Province [J]. China collective economy, 2020 (18): 34-36. 
[12] Lu Zhengwei. Renewable energy is supported by green finance [n]. Securities Daily, April 27, 2019 (A03).

[13] Wang Zhiguo. Research on green finance supporting the development of new energy industry [D]. Tianjin University of Finance and economics, 2019.

[14] Zhang Lu. Research on the coupling effect of green finance and new energy industry development -- An Empirical Analysis Based on the perspective of financial supply side Reform [J]. Journal of Jilin Institute of technology and technology, 2019, 35 (01): 92-98.

[15] Gao Xiaoyan, Jiao Yun, Ren Ziping, Wang Yuan. The realization path of green finance and energy industry in Beijing
Tianjin Hebei region [J]. North China finance, 2020 (02): 28-37.

[16] Gao Xiaoyan, Wang Zhiguo. Analysis of coupling mechanism between green finance and new energy industry [J]. Jianghan forum, 2017 (11): 42-47.

[17] Zhang Kezhen, Zhao Jianbo. Problems and suggestions of China's new energy technology innovation [J]. China's national conditions and strength, 2014 (11): 15-17.

[18] Liu Yao. Research on green finance development mechanism and Path Innovation in China [D]. Yunnan University of Finance and economics, 2020. 